\title{
Natural Organic Acid as Green Catalyst for Xanthenones Synthesis: Methodology, Mechanism and Calcium Channel Blocking Activity
}

\author{
Bruna S. Terra, ${ }^{a}$ Aura M. B. Osorio, ${ }^{a}$ Aline de Oliveira, ${ }^{a}$ Rebeca P. M. Santos, ${ }^{b}$ \\ Andressa P. Mouro, ${ }^{b}$ Natália F. de Araújo, ${ }^{b}$ Cameron C. da Silva, ${ }^{c}$ \\ Felipe T. Martins, ${ }^{c}$ Luciene B. Vieira ${ }^{b}$ Daniella Bonaventura, ${ }^{b}$ Heitor A. de Abreu, ${ }^{a}$ \\ Antonio F. C. Alcântara ${ }^{a}$ and Ângelo de Fátima ${ }^{*, a}$
}

${ }^{a}$ Departamento de Química and ${ }^{b}$ Departamento de Farmacologia, Universidade Federal de Minas Gerais, Av. Pres. Antônio Carlos, 6627, 31270-901 Belo Horizonte-MG, Brazil

'Instituto de Química, Universidade Federal de Goiás, Campus Samambaia, CP 131, 74001-970 Goiânia-GO, Brazil

\begin{abstract}
Xanthenones were synthesized via one-pot tricomponent reaction, under solvent-free conditions, using aldehydes, phenolic and cyclic 1,3-dicarbonyl compounds. Natural organic acids (NOAs), compounds present in many living metabolisms, were used as potential green catalysts. NOA are considered to be more eco-friendly and user-friendly alternative to traditional methodologies. Optimization studies showed that oxalic acid was the best NOA catalyst for such reaction furnishing the xanthenones with up to $93 \%$ of yield. Theoretical calculations were performed to evaluate this reaction mechanism and regioselectivity. The results showed that the regiospecificity of this three-component reaction is kinetically and thermodynamically controlled by the addition of $\beta$-naphthol $\mathrm{C} 2$, instead of $\mathrm{C} 10$, to the aldehyde. Our results also disclosed two xanthenones as novel calcium channels blockers. Eco-friendly reaction conditions, easy workup procedure, short reaction times and good yields are some of the advantages of our methodology.
\end{abstract}

Keywords: xanthenones, natural organic acid, theoretical calculations, calcium channels blockers

\section{Introduction}

Xanthones (Figure 1) are a class of oxygenated heterocycles that contain an aromatic ring fused to 4-carbonyl-pyran ring as the basic skeleton. ${ }^{1}$ They present several biological and pharmacologic properties: antivascular, antiarrhythmic, antihypertensive, antioxidant, anti-inflammatory, anticancer and calcium channel blocking. ${ }^{2}$ On the other hand, xanthenones (Figure 1), xanthone derivatives, are poorly explored regarding their biological properties, and described only for its anti-proliferative, ${ }^{3,4}$ antiviral $^{5}$ and anti-microbial properties. ${ }^{6}$

The literature describes the synthesis of xanthenones via a multicomponent reaction using a phenolic compound, an aldehyde, and a cyclic 1,3-dicarbonyl compound. ${ }^{7}$ Many Lewis or Brönsted acids may be used as catalysts: calixarenes, ${ }^{3}$

*e-mail: adefatima@qui.ufmg.br<smiles>O=c1c2ccccc2oc2ccccc12</smiles>

Xanthone<smiles>[R]C1C2=C(CCCC2=O)Oc2ccccc21</smiles>

Xanthenone
Figure 1. Xanthone and xanthenone base structure $(\mathrm{R}=$ aromatic or alkyl group).

ceric ammonium nitrate, ${ }^{4}$ polyethyleneglycol bound sulfonic acid, ${ }^{5}$ Hy zeolite, ${ }^{6}$ triflate proline, ${ }^{8}$ tetrabutyl ammonium fluoride, ${ }^{9}$ tri-methyl tetradecyl ammonium bromide, ${ }^{10}$ sulfamic acid ${ }^{11} p$-toluenesulfonic acid, ${ }^{12}$ triphenylphosphine$m$-sulfonate/carbon tetrabromide, ${ }^{13}$ phosphorus(V) oxide,,${ }^{14}$ indium(III) chloride, ${ }^{14}$ scandium(II) triflate, ${ }^{15}$ boron trifluoride diethyl etherate, ${ }^{16,17}$ functionalized ionic liquids, ${ }^{18} 2,4,6$-trichloro-1,3,5-triazine, ${ }^{19}$ silica-supported perchloric acid, ${ }^{20}$ succinimide- $N$-sulfonic acid, ${ }^{21}$ ytterbium perfluorooctanoate, ${ }^{22}$ thiamine hydrochloride ${ }^{23}$ and trityl 
chloride. ${ }^{24}$ However, most of these methods do not comply with environmental-friendly protocols, presenting one or more of the drawbacks: less availability or hard catalyst preparation, ${ }^{4,5,18,21,22}$ long reaction time, ${ }^{8,11,16,17,19,23}$ cumbersome product isolation procedures. ${ }^{16}$ They also use expensive and/or detrimental metal precursors, ${ }^{14,15,22}$ toxic catalysts, ${ }^{11,14}$ and toxic organic solvents to perform the reaction or purify the product. ${ }^{13,16,17,20}$ A readily available and non-hazardous catalyst that promotes the formation of xanthenones in a short reaction time, under solvent-free condition, and simple work-up is highly desirable.

A more eco-friendly and user-friendly alternative employs natural organic acids (NOAs), which are biodegradable compounds found in the metabolism of many organisms..$^{25,26}$ For example, acetic acid (the second simplest monocarboxylic acid after only to formic acid) catalyzes multicomponent reactions in the synthesis of 3 -alkoxyisoindolin-1-imines, ${ }^{27}$ piperidines, ${ }^{28}$ bicyclic pyro, ${ }^{29}$ quinazolinones and (dihydroquinazolinylphenyl) oxazolones. ${ }^{30}$ NOAs bearing two carboxylic groups and used as catalysts include the oxalic, malonic and succinic acids. Oxalic acid was reported as an efficient catalyst for the synthesis of coumarins, ${ }^{31}$ quinoxalines, ${ }^{32}$ quinolines,${ }^{33}$ bis(indolyl)methanes, ${ }^{34,35}$ tetrahydroquinolines ${ }^{36}$ and flavone. ${ }^{37}$ Although less explored in multicomponent reactions, oxalic acid has also shown to be an efficient catalyst in such reactions for obtaining quinazolinones, ${ }^{38}$ piperidines $^{39}$ and $\mathrm{N}$-aryl-3-aminodihydropyrrol-2-one4-carboxylates compounds. ${ }^{40}$ Malonic acid was reported as a catalyst in polymerization reactions ${ }^{41,42}$ and for obtaining 1,3-dichloropropanols from glycerol, ${ }^{43}$ however, its use in multicomponent reactions has not been described yet. Succinic acid was reported as a catalyst in a multicomponent reaction for the preparation of amidoalkyl naphthols ${ }^{44}$ and $\alpha$-amino phosphonates. ${ }^{45}$ Most of the NOAs come from economically renewable resources turning them as targets for developing green multicomponent approach for substances of pharmaceutical, agricultural, cosmetic and food purposes. ${ }^{25,45-48}$ Despite the several described uses of acetic, oxalic, malonic and succinic acids in organic synthesis, the literature has not registered their use to furnish xanthenones.

A probable mechanistic rationalization to produce xanthenones involves an ortho-quinone methide intermediate, which is generated by the nucleophilic attack of the phenolic compound on the aldehyde, followed by dehydration. ${ }^{3,11,14,15,20}$ Although this nucleophilic addition is reasonable, there is no discussion about the regioselectivity of the intermediate. Also, to the best of our knowledge, there are no theoretical and/or experimental studies about the mechanism proposition in the literature.
We developed a green methodology to synthesize xanthenones from the one-pot condensation of benzaldehyde derivatives, $\beta$-naphthol, and dimedone, employing NOAs as organic acid catalysts. The mechanism and regioselectivity were investigated using theoretical calculations HF/6-31G(d) and LC- $\omega$ PBE/6-311++G(d,p). Moreover, due to the high biological potential of xanthenones, we also investigated this class of molecules as calcium channel blockers.

\section{Results and Discussion}

\section{Optimization of the reaction conditions}

Initially, an investigation was performed to find the best catalyst and reaction condition to synthesize the xanthenone 4a (Table 1). As a reaction model, benzaldehyde (1.0 equivalent), $\beta$-naphthol (1.2 equivalent) and dimedone (1.5 equivalent) were mixed and catalytic amounts of oxalic $\left(\mathrm{pK}_{\mathrm{a} 1}=1.2\right)$, malonic $\left(\mathrm{pK}_{\mathrm{a} 1}=2.8\right)$, succinic $\left(\mathrm{pK}_{\mathrm{a} 1}=4.2\right)$, and acetic acids $\left(\mathrm{pK}_{\mathrm{a}}=4.7\right)(5,10$ and $20 \mathrm{mmol} \%)$ were added to reaction mixture. The evaluated organic acids follow a homologous series in which the number of carbons between the carboxyl groups varies; the oxalic having no carbon among them; the malonic acid has one carbon; the succinic acid has two carbons and the acetic acid is the corresponding monocarboxylic acid. The $\mathrm{pK}_{\mathrm{al}}$ value of dicarboxylic acids increases with the increase in the number of carbons between the carboxylates; a fact that can be explained by the inductive effect of the neighboring carboxyl and the stability of the corresponding conjugated base. The oxalic acid has the most stable conjugate base, because the negative charge can be stabilized by resonance and can establish an intramolecular hydrogen bond. Besides that, the other carbonyl in $\alpha$, increases its acidity by inductive effect.

We chose to develop a solvent-free under microwave radiation (MW) methodology because it makes the synthesis of xanthenones simpler, cleaner and more efficient. It also provides an increment on safety, easy work-up, cost reduction, and prevents solvent waste, hazards and toxicity. ${ }^{49-51}$

The catalyst quantity influences the xanthenone yields. Oxalic acid demonstrated itself to be the most efficient as a catalyst, providing similar or better yields than the other acids in all conditions.

The best condition was using $20 \mathrm{mmol} \%$ of oxalic acid and a reaction time of $5 \mathrm{~min}$ ( $82 \%$ yield; Table 1 ). This acid also showed that higher concentrations or longer reaction times lower the product yield. The behavior is opposite to the other acids, which improved the reaction yield with the 
Table 1. Effect of the type and quantity of natural organic acids (NOAs) for obtaining xanthenone $\mathbf{4} \mathbf{a}^{\mathrm{a}}$ under microwave radiation (MW) and solvent-free conditions

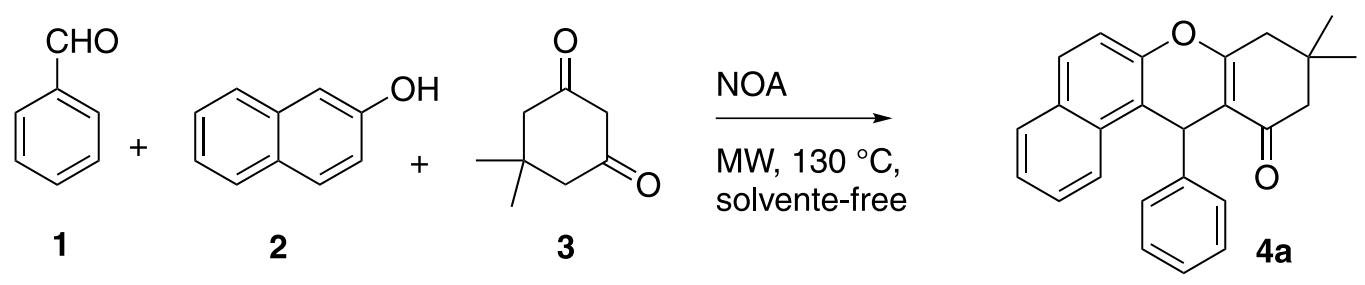

\begin{tabular}{|c|c|c|c|c|}
\hline entry & Natural organic acid (NOA) & NOA quantity / mmol $\%$ & time / min & Yield $^{\mathrm{b}} / \%$ \\
\hline 1 & oxalic acid & 5 & 5 & 58 \\
\hline 2 & oxalic acid & 5 & 10 & 51 \\
\hline 3 & oxalic acid & 10 & 5 & 62 \\
\hline 4 & oxalic acid & 10 & 10 & 52 \\
\hline 5 & oxalic acid & 20 & 5 & 82 \\
\hline 6 & oxalic acid & 20 & 10 & 65 \\
\hline 7 & oxalic acid & 25 & 5 & 66 \\
\hline 8 & malonic acid & 5 & 5 & 10 \\
\hline 9 & malonic acid & 5 & 10 & 26 \\
\hline 10 & malonic acid & 10 & 5 & 2 \\
\hline 11 & malonic acid & 10 & 10 & 51 \\
\hline 12 & malonic acid & 20 & 5 & 14 \\
\hline 13 & malonic acid & 20 & 10 & 55 \\
\hline 15 & succinic acid & 5 & 5 & 9 \\
\hline 15 & succinic acid & 5 & 10 & 35 \\
\hline 16 & succinic acid & 10 & 5 & 16 \\
\hline 17 & succinic acid & 10 & 10 & 21 \\
\hline 18 & succinic acid & 20 & 5 & 17 \\
\hline 19 & succinic acid & 20 & 10 & 54 \\
\hline 20 & acetic acid & 5 & 5 & traces \\
\hline 21 & acetic acid & 5 & 10 & 58 \\
\hline 22 & acetic acid & 10 & 5 & traces \\
\hline 23 & acetic acid & 10 & 10 & 51 \\
\hline 25 & acetic acid & 20 & 5 & 51 \\
\hline 25 & acetic acid & 20 & 10 & 67 \\
\hline 26 & no catalyst & - & 5 & 16 \\
\hline 27 & no catalyst & - & 10 & 20 \\
\hline
\end{tabular}

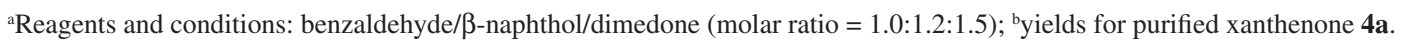

increase on the reaction time. The reaction carried out in absence of catalyst furnished the desirable product 4a in low yields (16 and 20\% after 5 and 10 min of MW, respectively). Oxalic acid is the most acid catalyst herein tested. Since the formation of xanthenones involves various protonated intermediates, the stronger Brönsted-Lowry acid should be the best organic catalyst.

Most protocols describe long reaction times (30 minutes to hours) for the xanthenone synthesis. . $^{811,16,17,19,23}$ The protocols using microwave radiation lasted less than 5-15 $\mathrm{min}^{15,18,22}$ however, these methodologies have disadvantages such as the need to prepare the catalysts, ${ }^{18,22}$ the use of detrimental metals as catalysts, ${ }^{15,22}$ and the use of toxic solvents to purify the desirable products. ${ }^{15}$ Our protocol takes only a few minutes to complete the reaction, uses a cheap, eco-friendly and user-friendly catalyst and all the xanthenones were purified by recrystallization. 
The scope of the substrates

We further investigated the scope of this methodology since the optimal conditions have been determined for the synthesis of xanthenone $\mathbf{4 a}$, using oxalic acid as the catalyst. Fifteen different xanthenones were synthesized with yields ranging 51-93\% (Table 2). Three kinds of aldehydes were tested: containing electron-donating groups, electronwithdrawing groups and heteroaromatic rings. The reaction yields were not considerably affected by the presence of electron-withdrawing groups (best result using 4-nitrobenzaldehyde; $80 \%$ yield) or electron-donating groups (best result using 2-hydroxy-benzaldehyde; $93 \%$ yield) in the aldehydes. The heteroaromatic aldehyde 2-pyridinyl provided the best yield at $130{ }^{\circ} \mathrm{C}(85 \%)$, demonstrating a greater stability at this temperature.

Low yields were observed for 4-hydroxybenzaldehyde (35\%), 4-cyano-benzaldehyde (45\%), 3-methoxy4-hydroxy-benzaldehyde $(46 \%)$ and 3,4-dimethoxy4-hydroxy-benzaldehyde (55\%), using the ratio aldehyde/ $\beta$-naphthol/dimedone of $1.0: 1.2: 1.5$. This is explained by the formation of subproducts from a side-reaction between the dimedone and the aldehyde. In order to prevent this side-reaction, the stoichiometry of $\beta$-naphthol and dimedone was inverted, for a ratio of aldehyde/ $\beta$-naphthol/ dimedone of 1.0:1.5:1.2, and we achieved better yields (Table 2, entries 7 and 10-12).

In all the cases, the pure product was readily isolated by recrystallization from methanol. The xanthenones products were characterized by melting point, infrared (IR), nuclear magnetic resonance (NMR) spectroscopy and an electrospray ionization high-resolution mass spectrometry (ESI-HRMS). Additional information was obtained from $\mathrm{X}$-ray diffraction spectroscopy.

\section{X-Ray}

The crystal structure of $\mathbf{4 e}$ was determined and analyzed in a diffractometer Enraf-Nonius Kappa-CCD. The ORTEP representation of $\mathbf{4 e}$ is shown in Figure 2 and data related to the collection and refinement of its crystal structure are in the Table S6 of the Supplementary Information (SI).

Compound $\mathbf{4 e}$ crystallized in centrosymmetric space groups, as expected from their achiral synthesis. The four

Table 2. Synthesis of xanthenones catalyzed by oxalic acid under solvent-free condition

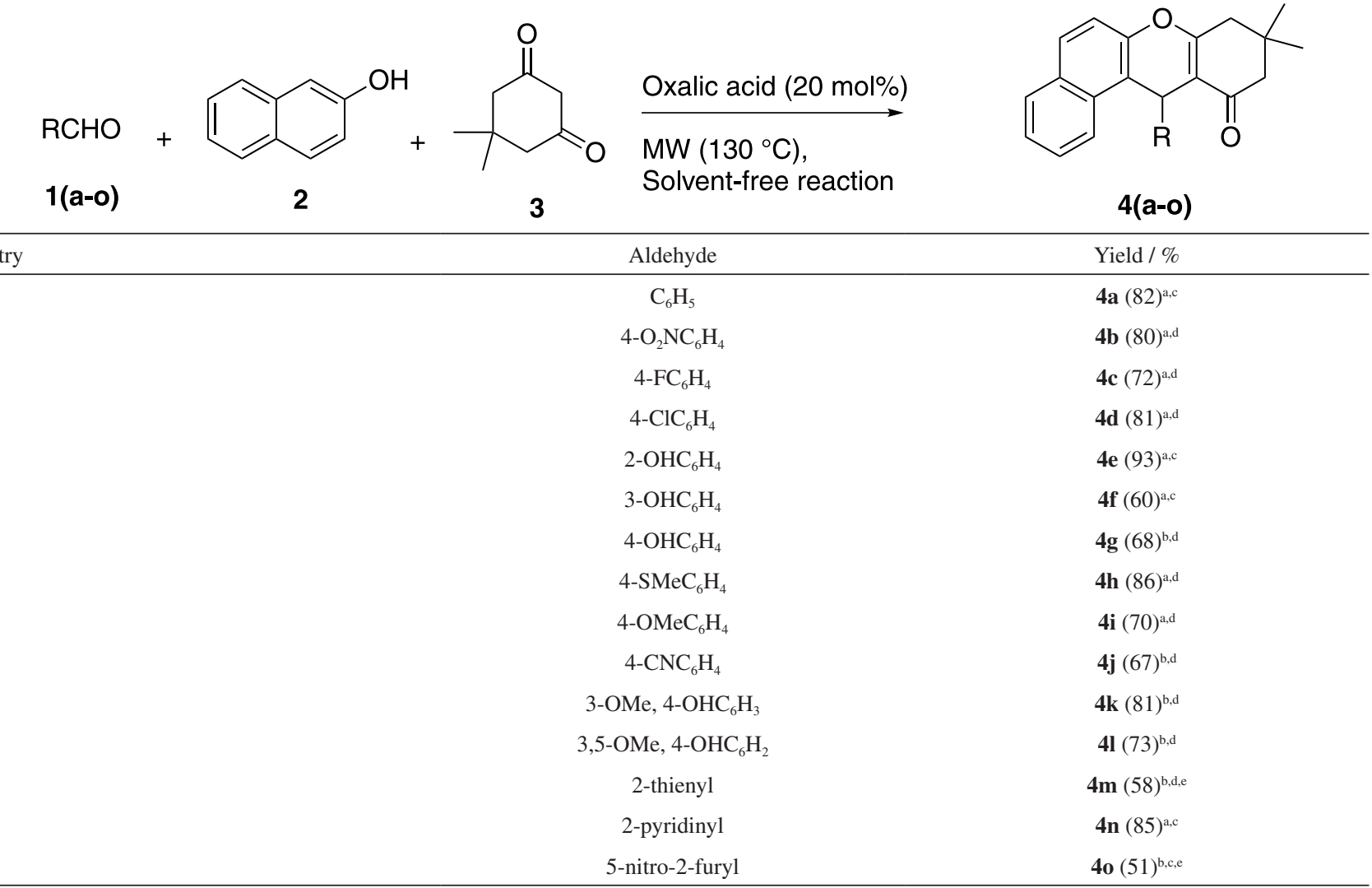

Molar ratio of the reagents used: a aldehyde/ $\beta$-naphthol/dimedone (1.0:1.2:1.5) or baldehyde/ $\beta$-naphthol/dimedone (1.0:1.5:1.2). Yield: for the pure xanthenone after ${ }^{\mathrm{c}} 5 \mathrm{~min}$ or ${ }^{\mathrm{d}} 10 \mathrm{~min}$ of reaction. ${ }^{\circ} \mathrm{The}$ temperature reaction used was $100^{\circ} \mathrm{C}$ instead of $130^{\circ} \mathrm{C}$. 


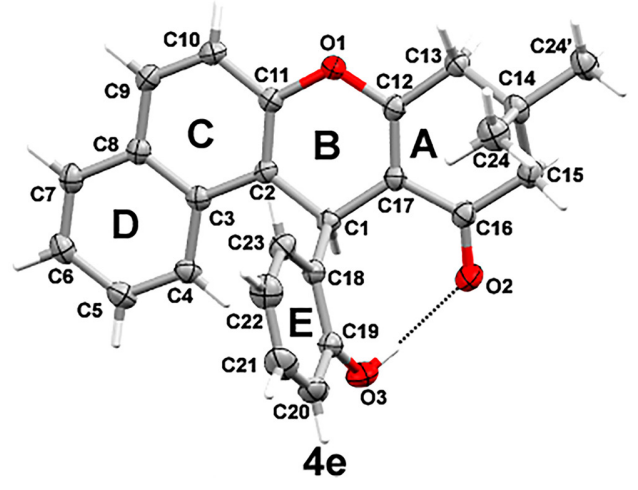

Figure 2. ORTEP image of 4e. Non-hydrogen atoms are shown with their $30 \%$ probability ellipsoids. Rings and non-hydrogen atoms are arbitrarily labeled.

fused rings formed a nearly planar xanthenone core except for ring $\mathrm{A}$, which adopted a half-chair conformation with the $\mathrm{C} 14$ carbon removed from the least-squares plane, calculated through the other five coplanar atoms, by 0.6451(15) $\AA$ in $\mathbf{4 e}$ (root-mean-square deviation (r.m.s.d.) of the C15-C16-C17-C12-C13 fitted atoms is $0.0194 \AA$ in 4e). Ring $B$ is distorted in with the $\mathrm{C} 1$ carbon deviating by $0.1857(14) \AA$ in $4 \mathbf{e}$ from the mean plane calculated through the $\mathrm{C} 2-\mathrm{C} 11-\mathrm{O} 1-\mathrm{C} 12-\mathrm{C} 17$ atoms (r.m.s.d. of the fitted atoms is $0.0245 \AA$ in $4 \mathbf{e}$ ). In the structure, the $\mathrm{C} 1$ and $\mathrm{C} 14$ are on the same side of the substituted phenyl ring that is perpendicular to the xanthenone mean plane. The mean plane calculated through ring E forms ca. $90^{\circ}$ angle $81.06(4)^{\circ}$ in $\mathbf{4 e}$ with the least-squares plane encompassing the non-hydrogen atoms of the four fused rings $\mathrm{A}-\mathrm{D}$, except for $\mathrm{C} 1$ and $\mathrm{C} 14$. In addition, there is a $S_{1}^{1}(8)$ motif in compound $4 \mathbf{e}$ due to the formation of an intramolecular hydrogen bonded cycle.

\section{Theoretical investigation of the reaction mechanism}

A probable mechanism to obtain xanthenones is via initial nucleophilic attack of $\beta$-naphthol (2) C2 on the carbonyl carbon of the benzaldehyde (1) (Scheme 1). , $^{3,11,14,15,20,24}$ An alternative mechanism would involve a nucleophilic attack<smiles>O=C(O)C(=O)OCc1ccccc1</smiles><smiles>Oc1ccc2ccccc2c1</smiles><smiles>O=C1C=Cc2ccccc2C1=C(O)c1ccccc1</smiles>



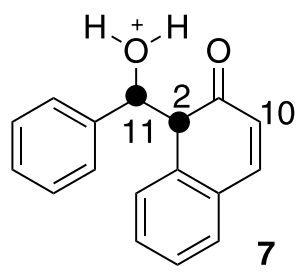<smiles>CC1(C)C[R9](=O)[C@H](C(=Cc2c(O)ccc3ccccc23)c2ccccc2)C(=O)O1</smiles><smiles>CC1(C)CC([O-])=C[C@H](O)C1</smiles><smiles>[O]C1C=Cc2ccccc2C1=Cc1ccccc1</smiles><smiles>C=C[OH+]C</smiles>
(Step 4)



(Step 7)



(Step 8) - $\mathrm{H}_{3} \mathrm{O}^{+}$<smiles>O=C1C=Cc2ccccc2C1=[V]c1ccccc1</smiles><smiles></smiles>

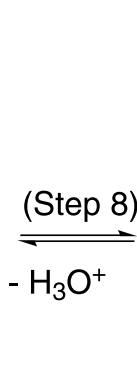<smiles>CC1(C)CC(=O)C2=C(C1)Oc1ccc3ccccc3c1[C@@H]2c1ccccc1</smiles>

Scheme 1. Probable mechanism for the synthesis of xanthenone (4) using $\beta$-naphthol (2) via C2 nucleophilic on the carbonyl carbon of the protonated benzaldehyde (5). 
of $\beta$-naphthol C10 (Scheme 2); however, this pathway leads to the xanthenone $\mathbf{2 0}$ that is not observed for this reaction. In order to verify this regioselectivity, theoretical calculations were performed.

The energy variation of each reaction step was calculated using HF/6-31G(d) level of theory. The electronic-nuclear energies, Gibbs free energies, and entropy values for all compounds in Schemes 1 and 2 are available in the Supplementary Information (Tables S1-S4).

Comparing both schemes and the energy step-by-step, we concluded that step 2 is crucial to explain the regioselectivity. In $\mathrm{C} 2$ pathway, this step is more favored by energy $\left(\Delta \mathrm{G}=-1.72 \mathrm{kcal} \mathrm{mol}^{-1}\right)$; however, in $\mathrm{C} 10$ pathway, this step is thermodynamically disfavored $\left(\Delta \mathrm{G}=10.51 \mathrm{kcal} \mathrm{mol}^{-1}\right.$, Tables S3 and S4).

In order to have a better regioselectivity understanding, a mechanistic study was also performed employing an improved level of theory (LC- $\omega$ PBE/6-311++G(d,p)). Scheme 3 shows the step 2 of both $\mathrm{C} 2$ and C10 pathways with their respective transition states (TS1 and TS2). All optimized structures and their energies are available in the Supplementary Information (Table S5).

The theoretical study at $130{ }^{\circ} \mathrm{C}$ showed that the activation energy (process $\mathbf{5}+\mathbf{2} \rightarrow \mathbf{T S}$, Table 3 ) to TS1 formation $\left(\Delta \mathrm{G}=6.84 \mathrm{kcal} \mathrm{mol}^{-1}\right)$ is lower than TS2 formation $\left(\Delta \mathrm{G}=15.45 \mathrm{kcal} \mathrm{mol}^{-1}\right)$. This demonstrates that the formation of $\mathbf{6}$ is thermodynamically and kinetically favorable, while the formation of $\mathbf{1 3}$ is not favorable (Figure 3).

The rate constants $\mathrm{k}$ of the reaction were estimated according to Eyring's equation (equation 1):

$\mathrm{k}(\mathrm{T})=\frac{\mathrm{k}_{\mathrm{B}} \mathrm{T}}{\mathrm{h}} \mathrm{e}^{-\Delta \mathrm{G}^{\ddagger} / \mathrm{RT}}$

In equation $1, \mathrm{~T}$ is temperature, $\mathrm{k}_{\mathrm{B}}$ is the Boltzmann's constant, $\mathrm{h}$ is the Planck's constant and $\mathrm{R}$ is the universal gas constant. The values were $6 \times 10^{7}$ and $3 \times 10^{1} \mathrm{~s}^{-1}$ at $130{ }^{\circ} \mathrm{C}$ for steps 2 (a) and 2 (b), respectively. This means that the formation of $\mathbf{6}$ is one billion times faster than the formation of $\mathbf{1 3}$. This study justifies the reason product 4<smiles>O=Cc1ccccc1C=[O+][O-]</smiles><smiles>Oc1ccc2ccccc2c1</smiles>

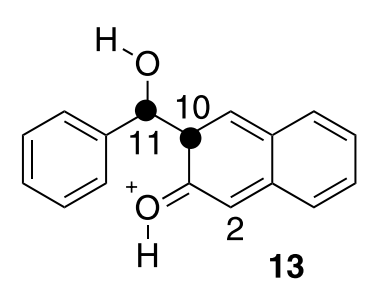

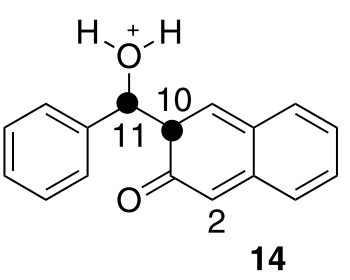



Scheme 2. Probable mechanism for the synthesis of xanthenone (20) using $\beta$-naphthol (2) via C10 nucleophilic on the carbonyl carbon of the protonated benzaldehyde (5). 
a)<smiles>O=C(O)c1ccccc1</smiles>

TS1



b)<smiles>O=C(O)c1ccccc1CCOc1cc2ccccc2cc1O</smiles>


TS2

Step 2 (b.II)

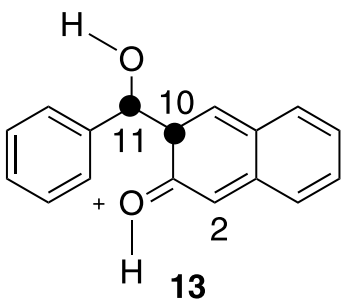

Scheme 3. Addition of $\beta$-naphthol (2) to protonated benzaldehyde (5) through nucleophilic attack of (a) C2 and (b) C10.

Table 3. Variations of electronic energy $\left(\Delta \mathrm{E}_{\text {elect }}\right)$, entropy $(\Delta \mathrm{S})$ and Gibbs free energy $\left(\Delta \mathrm{G}_{\text {total }}\right)$ to the studied steps at $130{ }^{\circ} \mathrm{C}$

\begin{tabular}{lccc}
\hline Process & $\begin{array}{c}\Delta \mathrm{E}_{\text {elect }} / \\
\left(\mathrm{kcal} \mathrm{mol}^{-1}\right)\end{array}$ & $\begin{array}{c}\Delta \mathrm{S} / \\
\left(\mathrm{cal} \mathrm{mol}^{-1} \mathrm{~K}^{-1}\right)\end{array}$ & $\begin{array}{c}\Delta \mathrm{G}_{\text {total }} / \\
\left(\mathrm{kcal} \mathrm{mol}^{-1}\right)\end{array}$ \\
\hline Step 2(a) ${ }^{\mathrm{a}}$ & & & \\
\hline $\mathbf{5 + 2} \rightarrow \mathbf{T S 1}$ & -11.97 & 4.65 & 6.84 \\
$\mathbf{T S 1} \rightarrow \mathbf{6}$ & -11.54 & 1.35 & -10.03 \\
$\mathbf{5 + 2} \rightarrow \mathbf{6}$ & -23.51 & 6.00 & -3.19 \\
\hline Step 2(b) $)^{\mathrm{a}}$ & & & \\
\hline $\mathbf{5 + 2} \rightarrow \mathbf{T S 2}$ & -2.73 & 2.05 & 15.45 \\
$\mathbf{T S 2} \rightarrow \mathbf{1 3}$ & -8.61 & 0.40 & -8.52 \\
$\mathbf{5 + 2} \rightarrow \mathbf{1 3}$ & -11.34 & 2.45 & 6.93 \\
\hline
\end{tabular}

The step 2 is completely sketched in Scheme 3.

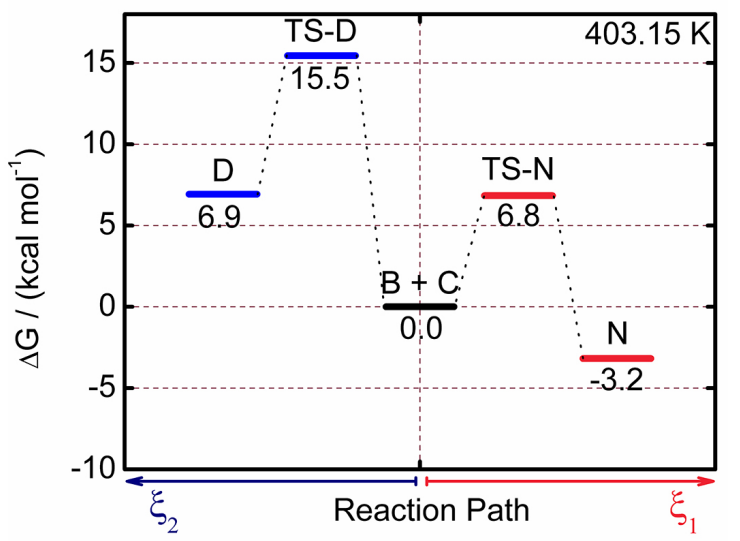

Figure 3. Energy profiles along the pathway for step 2(a) (data in red) and step 2(b) (data in blue) at $130^{\circ} \mathrm{C}$.

is obtained at the synthetic procedure while the product 20 is not observed.

The protonated benzaldehyde (5) suffers a nucleophilic attack receiving the charge density in its lowest unoccupied molecular orbital (LUMO) of the carbonyl carbon atom (Figure 4). The $\beta$-naphthol acts as a nucleophile donating charge density from its highest occupied molecular orbital (HOMO) passing through $\mathrm{C} 2$ and leading to 6 . The formation of $\mathbf{1 3}$ might occur by the nucleophilic attack of $\beta$-naphthol through its energetic nearest occupied orbital to the HOMO (i.e. HOMO - 1 orbital), which presents charge density passing through $\mathrm{C} 10$. This attack is less favorable than the first one because the HOMO -1 is less available than HOMO, and $19 \mathrm{kcal} \mathrm{mol}^{-1}$ highest in energy. Furthermore, the LUMO of 5 is energetically closer to the HOMO than to HOMO - 1 of $\beta$-naphthol. This corroborates with the thermodynamic and kinetics observations. The frontier orbitals of all studied species at $\mathrm{LC}-\omega \mathrm{PBE} / 6-311++\mathrm{G}(\mathrm{d}, \mathrm{p})$ level of theory are available in the Supplementary Information.

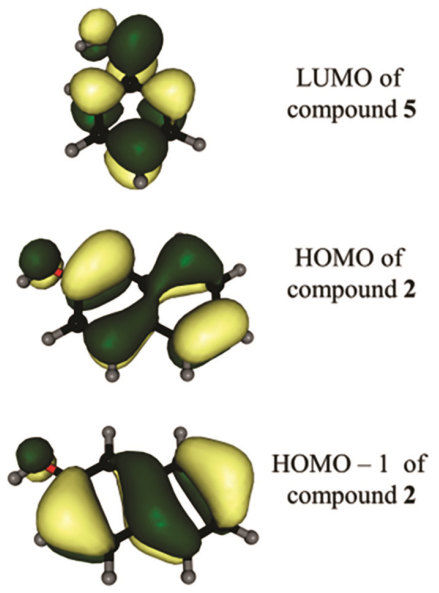

Figure 4. Frontier orbitals LUMO of protonated benzaldehyde (5), HOMO and HOMO - 1 of $\beta$-naphthol (2). Atom legends: C (black), $\mathrm{O}$ (red) and $\mathrm{H}$ (grey).

\section{Calcium influx assay}

Previously presented data by Wang et al., ${ }^{52}$ suggested the activity of several xanthones on blocking calcium channels 
$\left(\mathrm{Ca}^{2+}\right)$ and also beta adrenergic receptors. As xanthones are chemically related to xanthenones, we decided to verify the potential of the synthesized xanthenones as calcium channel blockers, and for that we performed an in vitro calcium influx assay using cortical brain synaptosomes. All xanthenones were evaluated to determine their potential to inhibit cytosolic $\mathrm{Ca}^{2+}$ entry when synaptosomes were depolarized by potassium chloride $(\mathrm{KCl}) 33 \mathrm{mM}$. The changes in cytosolic $\mathrm{Ca}^{2+}$ may reflect the $\mathrm{Ca}^{2+}$ influx and were monitored continuously in fura-2-loaded synaptosomes (as described in Experimental section). Figure 5 shows the results of the most promising xanthenones in inhibiting $\mathrm{Ca}^{2+}$ influx induced by high potassium. Depolarization by $\mathrm{KCl}$ led to an increase in intracellular calcium concentration $\left[\mathrm{Ca}^{2+}\right]_{\mathrm{i}}$, which was efficiently inhibited (ranging from 60 to $80 \%$ inhibition) by xanthenones (4c, $\mathbf{4 d}, \mathbf{4 e}, \mathbf{4 g}, \mathbf{4 h}, \mathbf{4 j}$, all at $200 \mathrm{mM}$ ) and also partially inhibited by a selective L-type $\mathrm{Ca}^{2+}$ channels blocker, nifedipine $(5 \mu \mathrm{M})$. As described in literature, ${ }^{53}$ the synaptosomes are commonly used to study synaptic transmission since they hold the molecular machinery necessary for the uptake, storage, and release of neurotransmitters. In addition to that, they have become common tools for drug testing. ${ }^{53,54}$ According to our data, nifedipine blockage did not completely abolish the increase in $\mathrm{Ca}^{2+}$ influx observed in synaptosomes. This data corroborates literature evidences which show that in synaptosomes just around $10 \%$ of $\mathrm{Ca}^{2+}$ channels are L-type and mostly are N-, P/Q-type or R-type channels.55,56 Furthermore, xanthenones displayed at Figure 5 were able to reduce $\mathrm{Ca}^{2+}$ influx to lower levels than nifedipine, suggesting that other $\mathrm{Ca}^{2+}$ channels might be blocked by those drugs. To clarify which channels are specifically blocked by those xanthenones detailed electrophysiological experiments would be required to test this hypothesis, which were beyond the scope of the present study.

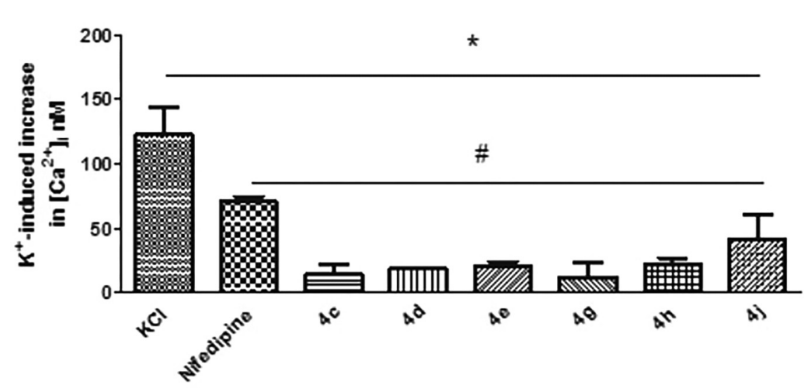

Figure 5. Effect of several xanthenones on the $\mathrm{KCl}$ induced cytosolic $\mathrm{Ca}^{2+}$ entry. The results are expressed as the mean \pm S.E.M. of three independent experiments. *Indicates a significant difference compared to $\mathrm{KCl}$ induced $\mathrm{Ca}^{2+}$ entry $(p<0.01)$. \#Indicates a significant difference compared to nifedipine $(p<0.01)$.

As several xanthenones were able to block $\mathrm{Ca}^{2+}$ influx in synaptosomes, we decided to test their effects on a model where L-type $\mathrm{Ca}^{2+}$ channels are mostly expressed..$^{57}$ Thus, we performed an assay to evaluate vascular contraction induced by $\mathrm{KCl}$. $\mathrm{KCl}$ induces vascular contraction due to vascular smooth muscle cell membrane depolarization by changing the potassium equilibrium potential and clamping the membrane potential at some value above the resting level. ${ }^{58}$ Membrane depolarization increases $\left[\mathrm{Ca}^{2+}\right]_{\mathrm{C}}$ (cytosolic calcium) through L-type $\mathrm{Ca}^{2+}$ channels, activating $\mathrm{Ca}^{2+} /$ calmodulin-dependent protein kinase II (CaMKII), which induces myosin light chain kinase phosphorylation and, consequently, vascular contraction. ${ }^{59}$ An important component of blood pression (BP) regulation is dependent on the contractile state of vascular smooth muscle cells (VSMCs), which is controlled to a large extent by the activities of KCNQ (subtype of potassium channel from $\mathrm{K}_{\mathrm{v}} 7$ family) and also L-type $\mathrm{Ca}^{2+}$ channels. ${ }^{60}$ Indeed, the clinical importance of $\mathrm{L}$-type $\mathrm{Ca}^{2+}$ channels blockers is sustained by its involvement in BP regulation.

Our results show that after all xanthenones from Figure 5 were tested, the pre-treatment with xanthenones $4 \mathbf{c}$ or $4 \mathbf{e}$ was able to reduce the maximum contraction effect $\left(E_{\text {max }}\right)$ induced by $\mathrm{KCl}$ in endothelium-denuded aortic rings (Figure 6 and Table 4) compared to the untreated control group. These results were in accordance to vascular effect induced by nifedipine which is a selective L-type $\mathrm{Ca}^{2+}$ channels blocker with most initial studies being performed in the early 1970s. Mikkelsen et al. (1979), ${ }^{61}$ as well as Pedersen et al. (1978), ${ }^{62}$ verified that nifedipine induced almost completely relaxation of arteries and veins pre-contracted by potassium. In the same way, Mikkelsen et al. $(1978)^{63}$ showed that nifedipine depressed the potassium contracture of human vessels. In vessels, vasoconstriction induced by $\mathrm{KCl}$ was inhibited by calciseptine (L-type $\mathrm{Ca}^{2+}$ blocker) or mibefradil (not selective T-type $\mathrm{Ca}^{2+}$ blocker) indicating

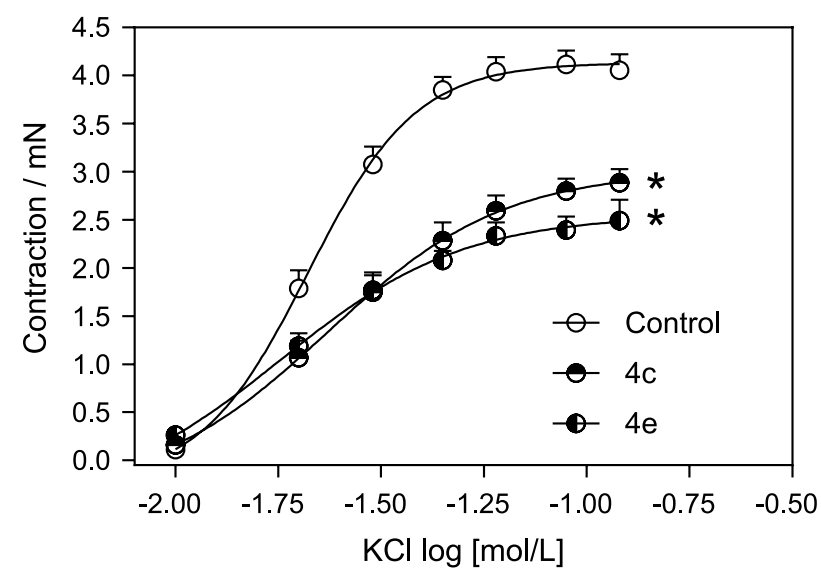

Figure 6. Effect of xanthenones on $\mathrm{KCl}$-induced contractile response in endothelium-denuded aortic rings. The concentration-response curves for $\mathrm{KCl}$ were determined in the absence of control or after incubation with $\mathbf{4 c}$ or $\mathbf{4 e}(100 \mu \mathrm{mol} \mathrm{L}-1)$. 
that in this vascular preparation, these calcium channels are necessary for vasoconstriction. ${ }^{64}$ Based in all these informations, our results suggest that xanthenones $\mathbf{4 c}$ and 4e could be partially blocking L-type $\mathrm{Ca}^{2+}$ channels, that are one of the main subtypes present in vascular tissue. ${ }^{61,62}$ More experiments to determine if those xanthenones may block another specific subtype of $\mathrm{Ca}^{2+}$ channel or may act in receptor-operated $\mathrm{Ca}^{2+}$ channels are needed to be studied to elucidate this point. We believed this data may be interesting in the identification of hypotensive and vasorelaxing activities of synthetic xanthenones.

Table 4. Effect of xanthenone $\mathbf{4 c}$ and $\mathbf{4 e}$ on the $E_{\max }$ for $\mathrm{KCl}$

\begin{tabular}{ll}
\hline Xanthenone $(100 \mu \mathrm{mol} \mathrm{L}$ & -1 \\
Control & $E_{\max } / \mathrm{mN}$ \\
$\mathbf{4 c}$ & $4.1 \pm 0.2(8)$ \\
$\mathbf{4 e}$ & $3.2 \pm 0.4^{\mathrm{a}}(4)$ \\
\hline
\end{tabular}

${ }^{\mathrm{a}}$ Compared to respective control group $(p<0.05$, ANOVA followed by Newman-Keuls). The number within parentheses indicates the number of animals. Values are mean \pm S.E.M.

\section{Conclusions}

The present work described an alternative green protocol for the preparation of xanthenones using natural organic acids as catalysts, under solvent-free and microwave irradiation conditions. The oxalic acid was the best catalyst and furnished the xanthenones in moderate to excellent yields (51-93\%). This protocol presented itself as being more eco-friendly and user-friendly alternative to traditional methodologies. The unprecedented theoretical study showed that the regioselectivity observed for such reaction is a consequence of the kinetic and thermodynamic control of the addition of $\beta$-naphthol $\mathrm{C} 2$, instead of the $\mathrm{C} 10$ atom, to the aldehyde. Additionally, our results have disclosed the xanthenones $\mathbf{4} \mathbf{c}$ and $\mathbf{4 e}$ as novel calcium channels blockers since these compounds were able to reduce the maximum contraction effect induced by $\mathrm{KCl}$ in endothelium-denuded aortic rings and also partially blocking L-type $\mathrm{Ca}^{2+}$ channels.

\section{Experimental}

\section{General techniques}

All starting materials were obtained from commercially available sources with high-grade purity and used without further purification. ${ }^{1} \mathrm{H}$ and ${ }^{13} \mathrm{C}$ NMR spectra at 200 and $400 \mathrm{MHz}$ were obtained on a Bruker AVANCE DPX 200 and a Bruker AVANCE DRX 400 spectrometer, respectively. The chemical shifts $(\delta)$ are expressed in parts per million (ppm) and are referenced to signals from tetramethylsilane (TMS) in the ${ }^{1} \mathrm{H}$ NMR spectra and deuterated solvent in the ${ }^{13} \mathrm{C}$ NMR spectra. ${ }^{1} \mathrm{H}$ NMR data are presented in the following order: chemical shift in ppm (multiplicity, integration, coupling constant $(J)$ in hertz $(\mathrm{Hz})$ ). Melting points (uncorrected) were obtained on a Mettler FP 80 HT apparatus. Infrared spectra were recorded on a PerkinElmer Spectrum One spectrophotometer. The high-resolution mass spectra were obtained using a mass spectrometer with an electrospray ionization source (ESI-MS) model Shimadzu LC-ITTOF.

Well-shaped single crystals of the xanthenone derivatives were chosen, mounted on a k-goniostat and exposed to graphite-monochromated X-ray beam (Mo K $\alpha$, $\lambda=0.71073 \AA$ ) using an Enraf-Nonius Kappa-CCD diffractometer equipped with a CCD camera of $95 \mathrm{~mm}$ lens. $\mathrm{X}$-Ray diffraction experiments were carried out at room temperature. The data collection strategy was calculated by setting $\varphi$ scans and $\omega$ scans with $\kappa$ offsets. No absorption correction was applied to the raw dataset due to the negligible absorption coefficient of the compounds using a Mo K $\alpha$ beam. The crystallographic software employed was as follows: COLLECT ${ }^{65}$ (X-ray diffraction experiment monitoring), HKL Denzo-Scalepack software package ${ }^{66}$ (indexing, integration and scaling of raw data), SIR2004 ${ }^{67}$ (structure solving), SHELXL-9768 (structure refinement), MERCURY ${ }^{69}$ and ORTEP-370 (structure analysis and graphical representations). Direct methods of phase retrieval were used to solve the crystal structures. All the non-hydrogen atoms in the asymmetric unit were located from the electronic density Fourier map. The early model was refined by the full-matrix least squares method based on F2. In the refinements, free anisotropic and fixed isotropic thermal displacement parameters were adopted for non-hydrogen and hydrogen atoms, respectively. The isotropic thermal displacement parameters of the hydrogens were either $20 \%$ (C-H hydrogens, except those in methyl moieties) or 50\% (hydrogens in methyl and hydroxyl moieties) greater than the equivalent isotropic parameter of the bonded atom. For the positions of the hydrogens, bond distances were stereochemically constrained according to the riding model.

\section{General procedure for the xanthenone synthesis}

For the xanthenone synthesis, aldehyde (1.0 mmol), $\beta$-naphthol (1.2 mmol), dimedone $(1.5 \mathrm{mmol})$ and organic acid $(5,10$ or $20 \mathrm{~mol} \%)$ were added to a $50 \mathrm{~mL}$ roundbottom flask under solvent-free conditions. The reaction proceeded under MW in a DISCOVER CEM ${ }^{\circledR}$ reactor, in a open flask mode, using the following conditions: temperature $130{ }^{\circ} \mathrm{C}$, maximum power $250 \mathrm{~W}$, hold time $3 \mathrm{~min}$, and run time 5 or $10 \mathrm{~min}$ at high stirring with an open 
tube. After completion of the reaction, methanol was added to the mixture, and the solid was filtered and recrystallized from methanol to afford the xanthenones in high purity.

\section{Theoretical methodology}

Theoretical calculations were performed using the Gaussian 09 program package. ${ }^{71}$ Gas phase optimization and evaluation of the harmonic frequencies at the $\mathrm{HF} / 6-31 \mathrm{G}(\mathrm{d}, \mathrm{p})$ level of theory were performed. Geometries were characterized as true minima in the potential energy surface (PES) when all vibrational modes were real.

It was employed the LC- $\omega \mathrm{PBE} / 6-311++\mathrm{G}(\mathrm{d}, \mathrm{p})$ level of theory ${ }^{72-76}$ as implemented at Gaussian 09 program. ${ }^{71}$ As criteria to geometry optimization convergence it was considered $10^{-7}$ Hartree to the energy and $10^{-6}$ Hartree Bohr $^{-1}$ to forces. The search for the transition states (TS) was done using QST3 method. ${ }^{77}$ Harmonic vibrational frequency calculations were conducted analytically for vibrational analysis. Intermediates of the mechanisms were species with all real harmonic frequencies in the PES, while the TSs present one imaginary frequency. Intrinsic reaction coordinate $\left(\right.$ IRC) ${ }^{78}$ calculations were carried out from each TS.

\section{Purification of synaptosomes}

Adult Swiss mice of both sexes (25-30 g) were decapitated and had their cortices removed and homogenized in $1: 10(\mathrm{~m} / \mathrm{v}) 0.32 \mathrm{M}$ sucrose solution containing dithiothreitol $(0.25 \mathrm{mM})$ and ethylenediamine tetraacetic acid (EDTA; $1 \mathrm{mM}$ ). Then, the homogenates were submitted to low-speed centrifugation $(1000 \times \mathrm{g}, 10 \mathrm{~min})$, and the synaptosomes were purified from the supernatant by discontinuous Percoll-density gradient centrifugation, ${ }^{79}$ as previously described ${ }^{80}$ The isolated nerve terminals were resuspended in Krebs-Ringer-HEPES solution (KRH; $124 \mathrm{mM}$ sodium chloride, $4 \mathrm{mM} \mathrm{KCl}, 1.2 \mathrm{mM}$ magnesium sulfate, $10 \mathrm{mM}$ glucose, $25 \mathrm{mM}$ HEPES, $\mathrm{pH}$ 7.4) with no added calcium chloride to a concentration of approximately $10 \mathrm{mg} \mathrm{mL}^{-1}$ followed by division into $200 \mu \mathrm{L}$ aliquots that were kept on ice until loaded with Fura-2 AM (stock solution $1 \mathrm{mM}$ in dimethyl sulfoxide) for $30 \mathrm{~min}$. The Ethics Committee in Animal Experimentation of the Federal University of Minas Gerais (CETEA/UFMG) approved all the in vivo experimental procedures under protocol number 139/2013.

Measurements of cytosolic $\mathrm{Ca}^{2+}$ concentration $\left[\mathrm{Ca}^{2+}\right]_{\mathrm{i}}$

Fura-2 AM measurements of the cytosolic calcium concentration $\left[\mathrm{Ca}^{2+}\right]_{\text {initial }}$ in synaptosomes were performed on a Biotek spectrofluorimeter according to Grynkiewicz et al. ${ }^{81}$ Calcium chloride was added to the synaptosomal suspension at the beginning of each fluorimetric assay $(1.0 \mathrm{mM}$ final concentration). Synaptosomes were stirred throughout the experiment in a plate maintained at $35^{\circ} \mathrm{C}$. Xanthenones were added to the synaptosomal suspension 10 minutes prior to membrane depolarization with $\mathrm{KCl}(33 \mathrm{mM})$. Baseline (240 s) measurements were obtained prior to the addition of drugs. At the end of each experiment, sodium dodecyl sulfate (SDS) $10 \%$ ( $0.1 \%$ final) was added to obtain maximal fluorescence $\left(\mathrm{R}_{\max }\right)$ by $3.0 \mathrm{M}$ Tris $+400.0 \mathrm{mM}$ EGTA (pH 8.6) to obtain minimal fluorescence $\left(\mathrm{R}_{\min }\right){ }^{81}$

Animals, vessel preparation and isometric tension measurements

Male Balb/c mice were housed under standard laboratory conditions with free access to food and water. Male Balb/c mice 8 to 12 weeks old (28-32 g) were killed by decapitation. The thoracic aorta was quickly removed, cleaned of adherent connective tissues and cut into rings (2-3 mm length). In all the rings, the endothelium was mechanically removed by gently rolling the lumen of the vessel on a thin wire. The aortic rings were placed between two stainless-steel stirrups and connected to an isometric force transducer (Letica Scientific Instruments; Barcelona, Spain) to measure the tension in the vessels. The rings were placed in an organ chamber containing Krebs solution with the following composition $\left(\mathrm{mmol} \mathrm{L}^{-1}\right)$ : sodium chloride, 135.0; KCl, 5.0; potassium dihydrogen phosphate, 1.17; calcium chloride, 2.5; $\mathrm{MgSO}_{4}$, 1.4; sodium bicarbonate, 20.0; glucose, 11.0. The solution was maintained at $\mathrm{pH} 7.4$ and gassed with $95 \%$ oxygen and $5 \%$ carbon dioxide at $37^{\circ} \mathrm{C}$. The rings were initially stretched to a basal tension of $0.5 \mathrm{~g}$, and then, they were allowed to equilibrate for $60 \mathrm{~min}$. Endothelial denudation was assessed qualitatively by the degree of relaxation induced by acetylcholine $\mathrm{EC}_{50}$ $(1 \mu \mathrm{mol} \mathrm{L}-1)$ in the presence of the contractile tone induced by phenylephrine $\left(0.1 \mu \mathrm{mol} \mathrm{L} \mathrm{L}^{-1}\right)$. For these studies with the endothelium-denuded vessels, the rings were discharged when there was more than $10 \%$ relaxation. The Ethics Committee in Animal Experimentation of the Federal University of Minas Gerais (CETEA/UFMG) approved all the in vivo experimental procedures under protocol number 164/2009.

Vascular contraction induced by potassium chloride $(\mathrm{KCl})$ in denuded mice aorta in the presence or absence of $4 c$ and $4 e$

The aortic rings without the endothelium were incubated with and without $4 \mathbf{c}$ or $4 \mathbf{e}\left(100 \mu \mathrm{mol} \mathrm{L}^{-1}\right)$ for 
30 minutes. After this time, the cumulative concentrationresponse curves for $\mathrm{KCl}(10-120 \mathrm{mM})$ were determined.

\section{Statistics}

The maximum effect $\left(E_{\max }\right)$ was considered to be the maximal amplitude response reached in the concentrationeffect curves for the relaxant agent. The data are expressed as the mean \pm S.E.M. (standard error of mean). In each set of experiments, the number of animals used (n) indicates the number of tissues studied. The differences between the mean values were assessed using one-way analysis of variance (ANOVA) followed by a Newman Keuls post-hoc test and values of $p<0.05$ were considered to be significant.

\section{Supplementary Information}

The experimental data, copies of ${ }^{1} \mathrm{H}$ NMR and ${ }^{13} \mathrm{C}$ spectra of all xanthenones synthesized, crystal data and refinement parameters of $\mathbf{4} \mathbf{e}$ and all information of theoretical studies are available free of charge at http://jbcs.org.br as a PDF file.

\section{Acknowledgments}

Financial support was obtained from the Coordenação de Aperfeiçoamento de Pessoal de Nível Superior (CAPES), Fundação de Amparo à Pesquisa do Estado de Minas Gerais (FAPEMIG) and Conselho Nacional de Desenvolvimento Científico e Tecnológico (CNPq). The authors are also grateful to Prof Rosemeire Brondi Alves (Department of Chemistry at Universidade Federal de Minas Gerais, Brazil) and Prof Fernando César de Macedo Júnior (Department of Chemisty at Universidade Estadual de Londrina, Brazil) for the suggestions and critical reading of this manuscript.

\section{References}

1. Fotie, J.; Bohle, D. S.; Anti-Infect. Agents Med. Chem. 2006, 5,15 .

2. Pinto, M. M. M.; Sousa, M. E.; Nascimento, M. S. J.; Curr. Med. Chem. 2005, 12, 2517.

3. da Silva, D. L.; Terra, B. S.; Lage, M. R.; Ruiz, A. L. T. G.; da Silva, C. C.; de Carvalho, J. E.; Carneiro, J. W. M.; Martins, F. T.; Fernandes, S. A.; de Fátima, A.; Org. Biomol. Chem. 2015, 13,3280 .

4. Kumar, A.; Sharma, S.; Maurya, R. A.; Sarkar, J.; J. Comb. Chem. 2010, 12, 20.

5. Naidu, K. R. M.; Krishna, B. S.; Kumar, M. A.; Arulselvan, P.; Khalivulla, S. I.; Lasekan, O.; Molecules 2012, 17, 7543.
6. Rama, V.; Kanagara, K.; Pitchumani, K.; Tetrahedron Lett. 2012, 53, 1018.

7. Khanna, R.; Dalal,A.; Kumar, R.; Kamboj, R. C.; ChemistrySelect 2016, 4, 840 .

8. Li, J.; Lu, L.; Su, W.; Tetrahedron Lett. 2010, 51, 2434.

9. Gao, S.; Tsai, C. H.; Yao, C. F.; Synlett 2009, 35, 3523.

10. Shinde, P. V.; Kategaonkar, A. H.; Shingate, B. B.; Shingare, M. S.; Beilstein J. Org. Chem. 2011, 7, 53.

11. Heravi, M. M.; Alinejhad, H.; Bakhtiari, K.; Oskooie, H. A.; Mol. Diversity 2010, 14, 621.

12. Khurana, M.; Magoo, D.; Tetrahedron Lett. 2009, 50, 4777.

13. Huo, C.-D.; Bao, X.-Z.; Hu, D.-C.; Jia, X.-D.; Sun, C.-G.; Wang, C.; Chin. Chem. Lett. 2014, 25, 699.

14. Nandi, G. C.; Samai, S.; Kumar, R.; Singh, M. S.; Tetrahedron 2009, 65, 7129.

15. Rao, M. S.; Chhikara, B. S.; Tiwari, R.; Shirazi, A. N.; Parang, K.; Kuma, A.; Monatsh. Chem. 2012, 143, 263.

16. Sethukumar, A.; Chandy, M. M.; Prakasam, B. A.; Pallepogu, R.; Struct. Chem. 2011, 22, 671.

17. Sethukumar, A.; Vithya, V.; Kumar, C. U.; Prakasam, B. A.; J. Mol. Struct. 2012, 1008, 8.

18. Kundu, D.; Majee, A.; Hajra, A.; Green Chem. Lett. Rev. 2011, 4, 205.

19. Zhang, Z.-H.; Zhang, P.; Peng, Y.; Yang, S. H.; Wang, H. J.; Deng, J.; J. Chem. Sci. 2010, 122, 427.

20. Wu, L.; Wu, Y.; Yan, F.; Fang, L.; Monatsh. Chem. 2010, 141, 871.

21. Shirini, F.; Khaligh, N. G.; Dyes Pigm. 2012, 95, 789.

22. Sundar, C. S.; Rao, K. U. M.; Reddy, N. B.; Reddy, M. V. N.; Prasad, S. S.; Reddy, C. S.; Catal. Sci. Technol. 2012, 2, 1382.

23. Fatma, S.; Singh, P. K.; Ankit, P.; Shireen; Singh, M.; Singh, J.; Tetrahedron Lett. 2013, 54, 6732.

24. Khazaei, A.; Zolfigol, M. A.; Moosavi-Zare, A. R.; Zare, A.; Khojasteh, M.; Asgari, Z.; Khakyzadeh, V.; Khalafi-Nezhad, A.; Catal. Commun. 2012, 20, 54.

25. Zeikus, J. G.; Jain, M. K.; Elankovan, P.; Appl. Microbiol. Biotechnol. 1999, 51, 54.

26. Suresh; Saini, A.; Kumar, D.; Sandhu, J. S.; Green Chem. Lett. Rev. 2009, 2, 29.

27. Shen, S.; Xu, X.; Lei, M.; Hu, L.; Synthesis 2012, 44, 3543.

28. Lashkari, M.; Maghsoodlou, M. T.; Hazeri, N.; Habibi-Khorassani, S. M.; Sajadikhah, S. S.; Doostmohamadi, R.; Synth. Commun. 2013, 43, 635.

29. Chen, X.-B.; Wang, X.-Y.; Zhu, D.-D.; Yan, S.-J.; Lin, J.; Tetrahedron 2014, 70, 1047.

30. Fozooni, S.; Firoozi, H.; Chem. Heterocycl. Compd. 2015, 51, 340.

31. Kokare, D.; Sangshetti, J. N.; Shindea, D. B.; Synthesis 2007, 18, 2829.

32. Hasaninejad, A.; Zare, A.; Mohammadizadeh, M. R.; Shekouhya, M.; ARKIVOC 2008, xiii, 28. 
33. Dabiri, M.; Baghbanzade, M.; Nikcheh, M. S.; Monatsh. Chem. 2007, 138, 1249.

34. Kokare, N. D.; Sangshetti, J. N.; Shinde, D. B.; Chin. Chem. Lett. 2008, 19, 1186.

35. Dabiri, M.; Baghbanzadeh, M.; Azimi, S. C.; Ahmadzadeh-Asl, S.; Ardestani, R. R.; Lett. Org. Chem. 2008, 5, 490.

36. Nagarajan, R.; Perumal, P. T.; Synth. Commun. 2001, 31, 1733.

37. Zambare, A. S.; Sangshett, J. N.; Kokare, N. D.; Shinde, D. B.; Chin. Chem. Lett. 2009, 20, 171.

38. Sangshetti, J.-N.; Kokare, N.-D.; Shinde, D.-B.; Chin. J. Chem. 2008, 26, 1506.

39. Sajadikhala, S. S.; Maghsoodlou, M. T.; Hazeri, N.; HabibiKhorassani, S. M.; Willis, A. C.; Chin. Chem. Lett. 2012, 23, 569.

40. Sajadikhala, S. S.; Hazeria, N.; Maghsoodloua, M. T.; HabibiKhorassania, S. M.; Khandan-Baranib, K.; J. Chem. Res. 2013, 37,40 .

41. Behaki, K.; Gupta, K. C.; Raja, G. D.; Das, P.; Acta Polym. 1991, 42, 206.

42. Erbil, C.; Eur. Polym. J. 1999, 35, 1747.

43. Herliati; Yunus, R.; Rashid, U.; Abidin, Z. Z.; Ahamad, I. S.; Asian J. Chem. 2014, 26, 2907.

44. Hazeri, N.; Maghsoodlou, M. T.; Habibi-Khorassani, S. M.; Aboonajmi, J.; Lashkari, M.; Sajadikhah, S. S.; Res. Chem. Intermed. 2014, 40, 1781.

45. Hazeri, N.; Maghsoodlou, M. T.; Habibi-Khorassani, S. M.; Aboonajmi, J.; Safarzaei, M.; Chem. Sci. Trans. 2013, 2, S330.

46. Partridge, E. P.; Ind. Eng. Chem. 1931, 23, 482.

47. Hromatka, O.; Ebner, H.; Ind. Eng. Chem. 1959, 51, 1279.

48. Kayashima, T.; Katayama, T.; Biochim. Biophys. Acta 2002, 1573, 1 .

49. Varma, R. S.; Green Chem. 1999, 43.

50. Tanaka, K.; Toda, F.; Chem. Rev. 2000, 100, 1025.

51. Lidstron, P.; Tierney, J.; Wathey, B.; Westman, J.; Tetrahedron 2001, 57, 9225.

52. Wang, L. W.; Kang, J. J.; Chen, I. J.; Teng, C. M.; Lin, C. N.; Bioorg. Med. Chem. 2002, 10, 576.

53. Breukel, A. I.; Besselsen, E.; Ghijsen, W. E.; Methods Mol. Biol. 1997, 72, 33.

54. Ghijsen, W. E.; Leenders, A. G.; da Silva, L. F. H.; Neurochem. Res. 2003, 28, 1443.

55. Olivera, B. M.; Miljanich, G. P.; Ramachadran, I.; Adams, M. E.; Annu. Rev. Biochem. 1994, 63, 823.

56. Vieira, L. B.; Kushmerick, C.; Reis, H. J.; Diniz, C. R.; Cordeiro, M. N.; Prado, M. A.; Kalapothakis, E.; Romano-Silva, M. A.; Gomez, M. V.; Neurochem. Int. 2003, 42, 277.

57. Goligorsky, M. S.; Colflesh, D.; Gordienko, D.; Moore, L. C.; Am. J. Physiol. 1995, 268, F251.

58. Bolton, T. B.; Physiol. Rev. 1979, 59, 606.

59. Tansey, M. G.; Word, R. A.; Hidaka, H.; Singer, H. A.; Schworer, C. M.; Kamm, K. E.; Stull, J. T.; J. Biol. Chem. 1992, 267, 12511 .
60. Brueggemann, L. I.; Mani, B. K.; Mackie, A. R.; Cribbs, L. L.; Byron, K. L.; Mol. Cell. Pharmacol. 2010, 2, 15.

61. Mikkelsen, E.; Anderson, K. E.; Pedersen, O. L.; Acta Pharmacol. Toxicol. (Copenh) 1979, 44, 110.

62. Pedersen, O. L.; Mikkelsen, E.; Anderson, K. E.; Acta Pharmacol. Toxicol. (Copenh) 1978, 43, 137.

63. Mikkelsen, E.; Anderson, K. E.; Pedersen, O. L.; Acta Pharmacol. Toxicol.(Copenh) 1978, 43, 291.

64. Cribbs, L. L.; Circ. Res. 2001, 89, 560.

65. COLLECT, Data Collection Software, Nonius, Delft, 1998.

66. Otwinowski, Z.; Minor W. In Methods in Enzymology: Macromolecular Crystallography, Part A, vol. 276, $1^{\text {st }}$ ed.; Carter Jr., C. W.; Sweet, R. M., eds.; Academic Press: New York, 1997.

67. Burla, M. C.; Caliandro, R.; Camalli, M.; Carrozzini, B.; Cascarano, G. L.; de Caro, L.; Giacovazzo, C.; Polidori, G.; Spagna, R.; J. Appl. Crystallogr. 2005, 38, 381.

68. Sheldrick, G. M.; Acta Crystallogr., Sect. A 2008, 64, 112.

69. Bruno, I. J.; Cole, J. C.; Edgington, P. R.; Kessler, M. K.; Macrae, C. F.; McCabe, P.; Pearson, J.; Taylor, R.; Acta Crystallogr., Sect. B 2002, 58, 389.

70. Farrugia, L. J. J.; Appl. Crystallogr. 1997, 30, 565.

71. Frisch, M. J.; Trucks, G. W.; Schlegel, H. B.; Scuseria, G. E.; Robb, M. A.; Cheeseman, J. R.; Montgomery, J. A.; Vreven, T.; Kudin, K. N.; Burant, J. C.; Millam, J. M.; Iyengar, S. S.; Tomasi, J.; Barone, V.; Mennucci, B.; Cossi, M.; Scalmani, G.; Rega, N.; Petersson, G. A.; Nakatsuji, H.; Hada, M.; Ehara, M.; Toyota, K.; Fukuda, R.; Hasegawa, J.; Ishida, M.; Nakajima, T.; Honda, Y.; Kitao, O.; Nakai, H.; Klene, M.; Li, X.; Knox, J. E.; Hratchian, H. P.; Cross, J. B.; Adamo, C.; Jaramillo, J.; Gomperts, R.; Stratmann, R. E.; Yazyev, O.; Austin, A. J.; Cammi, R.; Pomelli, C.; Ochterski, J. W.; Ayala, P. Y.; Morokuma, K.; Voth, G. A.; Salvador, P.; Dannenberg, J. J.; Zakrzewski, V. G.; Dapprich, S.; Daniels, A. D.; Strain, M. C.; Farkas, O.; Malick, D. K.; Rabuck, A. D.; Raghavachari, K.; Foresman, J. B.; Ortiz, J. V.; Cui, V.; Baboul, A. G.; Clifford, S.; Cioslowski, V.; Stefanov, B. B.; Liu, G.; Liashenko, A.; Piskorz, P.; Komaromi, I.; Martin, R. L.; Fox, D. J.; Keith, T.; Al-Laham, M. A.; Peng, C. Y.; Nanayakkara, A.; Challacombe, M.; Gill, P. M. W.; Johnson, B.; Chen, W.; Wong, M. W.; Gonzalez, C.; Pople, J. A.; GAUSSIAN 09, Gaussian Inc., Pittsburgh, PA, 2009.

72. Hey, J.; Scuseria, G. E.; Ernzerhof, M.; J. Chem. Phys. 2003, $118,8207$.

73. Hey, J.; Scuseria, G. E.; Ernzerhof, M.; J. Chem. Phys. 2006, 124, 229906.

74. Vydrow, O. A.; Heyd, J.; Krukau, A. V.; Scuseria, G. E.; J. Chem. Phys. 2006, 124, 074106.

75. Vydrov, O. A.; Scuseria, G. E.; J. Chem. Phys. 2006, 125, 234109.

76. Vydrow, O. A.; Scuseria, G. E.; Perdew, J. P.; J. Chem. Phys. 2007, 126, 154109. 
77. Dykstra, C. E.; Theory and Applications of Computational Chemistry: The First Forty Years, $1^{\text {st }}$ ed.; Elsevier: Amsterdam, 2005.

78. Fukui, K.; Acc. Chem. Res. 1981, 14, 363.

79. Dunkley, P. R.; Heath, J. H.; Harrison, S. M.; Jarvi, P. E.; Gleenfield, P. J.; Rostas, J. A. P.; Brain Res. 1988, 44, 59.
80. Romano-Silva, M. A.; Santos, R. R.; Gomez, M. V.; Diniz, C. R.; Cordeiro, M. N.; Brammer, M. J.; Biochem. J. 1993, 296, 313.

81. Grynkiewicz, G.; Poenie, M. E.; Tsien, R. Y.; J. Biol. Chem. 1985, 260, 3440.

Submitted: January 30, 2017

Published online: May 9, 2017 